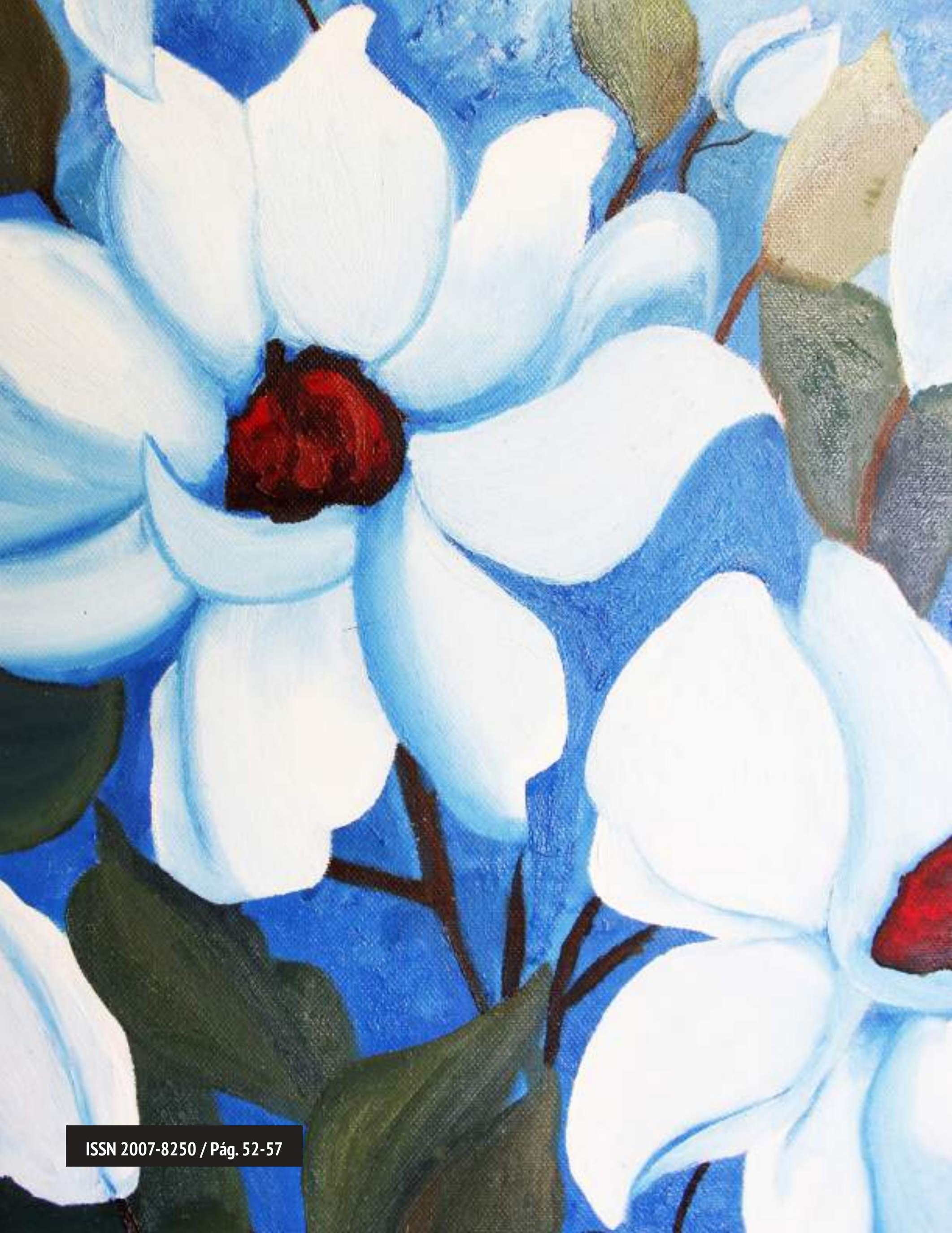




\section{FACTORES QUE INFLUYEN EN ALGUNOS PROBLEMAS DE LOS ADOLESCENTES}

\section{Profr. Gustavo Padrón Alonso}

No. 10 - Mayo 1994

INTRODUCCIÓN

on mi modesta experiencia de trabajar con adolescentes, atendiendo actualmente el área de Orientación Vocacional en el nivel de Preparatoria, con el deseo de contribuir al examen de algunos problemas relacionados con la educación de la juventud; y gracias a la lectura de algunos artículos de experimentados educadores y psicólogos de quienes retomé lo escrito por ellos sobre este tema, me resulta tan importante para padres y maestros y con el debido respeto a los maestros Humberto Ramos Lozano,Aníbal Ponce y Stanley y Halles, es que me atrevo a plantear lo siguiente: 


\section{ETAPAS DE LA VIDA HUMANA}

a vida del hombre es indivisible.

Se desenvuelve como un proceso unitario que va desde el nacimiento, su tránsito por el mundo, hasta su declinación y desenlace final con la muerte.

Este proceso continuo del existir puede ser examinado a la luz de diversas épocas o etapas que presentan caracteres especiales y que permiten un examen independiente, aunque ligado de cada una de ellas. Estas etapas de la vida humana se desglosan en:

- Infancia o Niñez

- Pubertad y Adolescencia

- Juventud

- Edad Madura,

- Vejez y Senectud

Muchos de estos períodos se subdividen en etapas internas como primera, segunda y tercera infancia, que cobijadas con caracteres generales idénticos presentan aspectos específicos.

Estos períodos de maduración de la vida se singularizan por el grado de desarrollo observable en diversos renglones de la actividad del ser humano: esfera somática, física o corporal; psicológica con acentuación en los procesos del pensar y de la inteligencia; afectiva-emocional y esfera cognitiva, con expresión de los fenómenos de la voluntad y de la conducta. El grado de desarrollo de estos diversos apartados de la personalidad caracterizan las etapas de la infancia, adolescencia, juventud, etc.

\section{LA EDUCACIÓN MEDIA ES UN NIVEL EDUCATIVO DE LOS ADOLESCENTES}

La escuela primaria atiende a los niños, la educación media a los adoles-

\section{En forma un tanto arbitraria se hace concluir el período de la infancia a la altura de los 11 y 12 años, en tanto que la adolescencia se inicia con la pubertad}

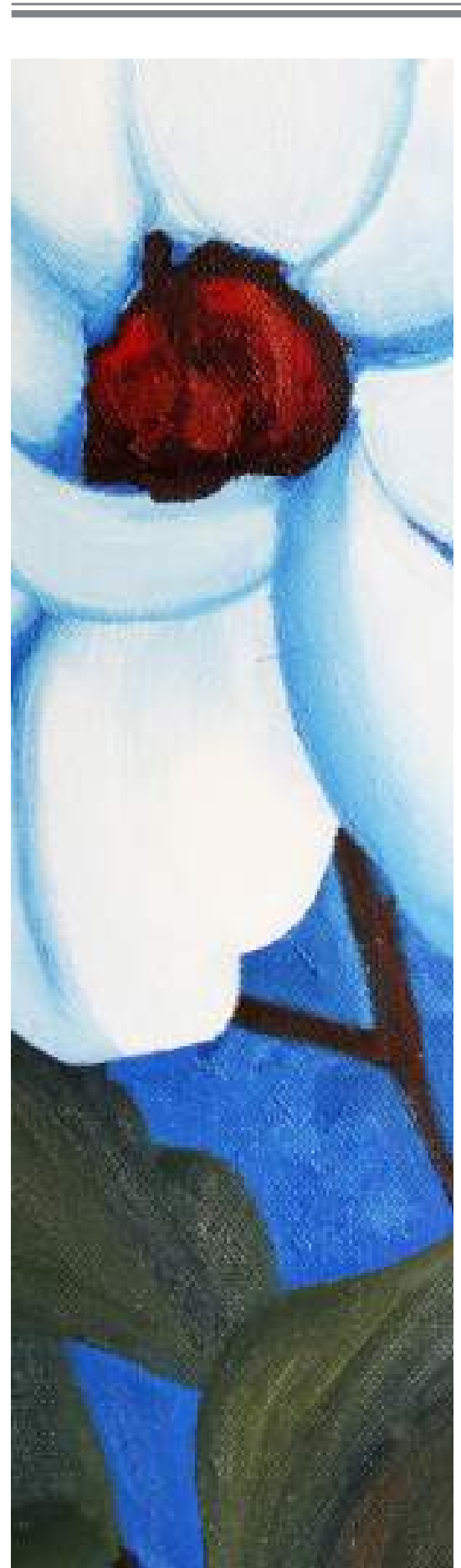

centes y la educación superior a los jóvenes. En forma un tanto arbitraria se hace concluir el período de la infancia a la altura de los 11 y 12 años, en tanto que la adolescencia se inicia con la pubertad, a partir de esas edades hasta los 18 años.

\section{LOS ADOLESCENTES}

El adolescente no es un niño, pero tampoco es un hombre. Se encuentra en un período de transición, de crecimiento, como lo indica la etimología de la palabra adolecere: crecer. Es un período de rápido desarrollo.

Múltiples investigaciones se han hecho de esta interesante etapa de la vida. Las personas ajenas al estudio de los problemas educativos, y muchos padres de familia, se muestran sorprendidos de los cambios repentinos que se observan en este período. No pocos problemas derivan de la incomprensión de los adultos respecto a las transformaciones que sufren los muchachos que llegan a esta edad.

El carácter tornadizo y la conducta de los adolescentes se explican, entre otras causas, por su inestabilidad emocional. Muchos motivos existen para el aumento de la emotividad juvenil. Los muchachos en esta edad son difíciles de manejar. Sus sentimientos son inestables y a ello 
obedeció que Stanley Hall llamara a este período Época de la Tormenta y la Tensión.

\section{PRINCIPALES PROBLEMAS DE LOS ADOLESCENTES}

Quienes se dedican al estudio especializado de esta edad resumen sus problemas en los siguientes:

1. Crisis puberal y transformaciones somáticas y fisiológicas.

2. Cambios en el psiquismo y alteración de sentimientos vitales.

3. Erotización de la individualidad.

4. Incorporación a la vida social.

5. Ajustes al hogar.

6. El enigma de la vocación.

7. El instinto autosertivo y la proyección del $Y O$ al futuro.

8. La concepción axiológica y la problemática de las diversas ideologías.

Creemos sea bastante con afirmar que los cambios que se operan en la adolescencia son evidentes, no tan sólo por lo que se refiere a las alteraciones morfológicas: aparición del bozo, modificación de la voz, alargamiento manifiesto en las extremidades, aparición de los caracteres sexuales secundarios, etc.; sino por las profundas modificaciones en la conducta, la vida afectiva y en lo problemático y tornadizo del carácter. Alguien llamó a la adolescencia:

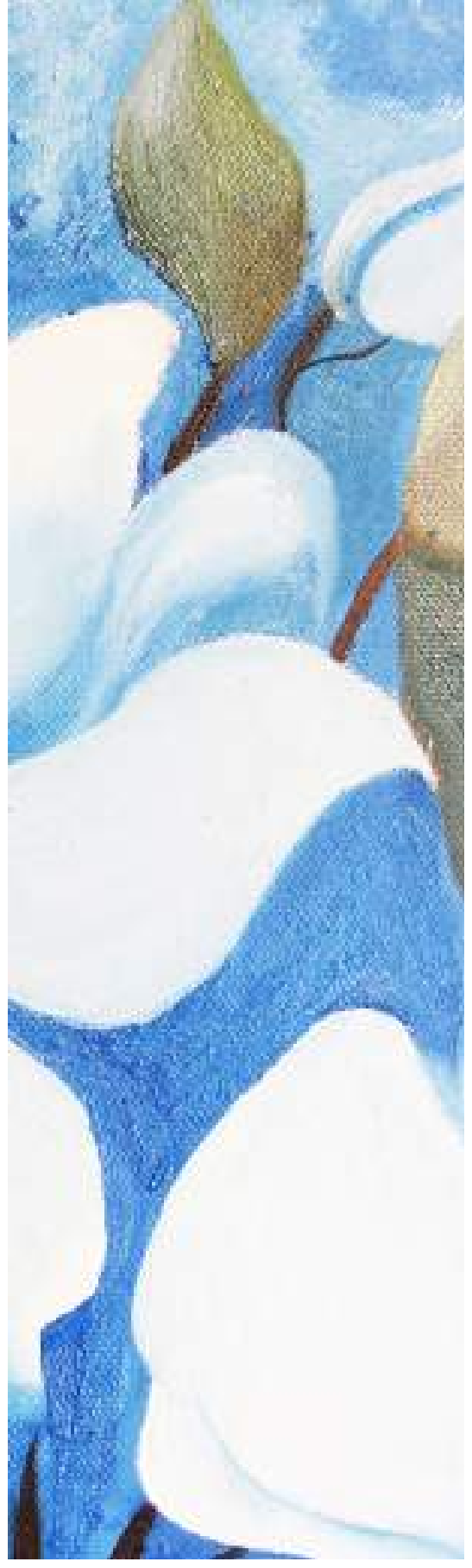

Los cambios que se operan en la adolescencia son evidentes (...) por las profundas modificaciones en la conducta, la vida afectiva y en lo problemático y tornadizo del carácter
Segundo Nacimiento, y en cierto sentido tenía razón. Deseo referirme exclusivamente a los siguientes problemas de los adolescentes:

1. Crisis puberal

2. Fracasos escolares

3. Formación del carácter

4. Lucha contra el medio ambiente

\section{A). Crisis Puberal}

El paso de la niñez a la pubertad provoca en los muchachos un estado de inquietud y de ansiedad que no se explican. La raíz de esta extraña sensación que experimentan los adolescentes, Aníbal Ponce la ha denominado Nueva Cenestesia.

Lo que le sucede es originado por un doble motivo: el funcionamiento de las glándulas endocrinas y, principalmente, la erotización de la individualidad causada por el advenimiento de la pubertad que hace que las gónadas viertan sus hormonas en el torrente sanguíneo, para producir la aparición de los caracteres sexuales secundarios; y por otra parte, la repercusión de estos cambios en el psiquismo que, básicamente, se manifiestan por el deseo de llegar a ser hombre.

El afán de independencia respecto de la constelación familiar y de los maestros, las actitudes de rebeldía, los deseos de notoriedad y las formas raras de conducta y de inadaptación observables en los adolescentes, son resultados de esta crisis puberal.

El muchacho preocupado por los cambios que observa en su constitución somática, por el acné de su cara, por su crecimiento inusitado o por el retardo de su desarrollo, por la incertidumbre en el futuro, por su deseo 
de ser comprendido y considerado ya como un adulto, se vuelve irascible, inestable y rebelde. Le molesta la tutela excesiva de los padres, le incomoda que no le permitan dar rienda suelta a su afán de plena libertad.

La actitud de los padres de familia suele ser de extrema condescendencia hacia sus hijos; otras veces, es de exagerada severidad. Ni una ni otra actitud son aconsejables. Debe guardarse una posición intermedia, pues es indebido dejar hacer a los muchachos todo lo que desean, cumplirles todos sus caprichos; como también, no es prudente extremar el rigor y tratar de hacerse obedecer mediante el ejercicio de la autoridad. Hay que tratar al adolescente de suerte que comprenda que se le otorgan ciertas libertades pero que no se le toleran libertinajes.

\section{B). Fracasos Escolares}

El objetivo fundamental de la educación media se ha dicho, muchas veces, es formativo. Por formativo debe entenderse la preocupación por lograr un desarrollo armónico de los diversos aspectos de la personalidad.

Antaño la finalidad esencial de los diversos niveles de la enseñanza era la instrucción, es decir, el desarrollo fundamental de los procesos intelectuales y de manera especial, el rendimiento escolar. Nadie puede despreciar el saber, pero éste no es el todo del desarrollo de una individualidad. El régimen escolar continúa acentuando su interés por el aspecto del aprendizaje.

Uno de los problemas que los adolescentes confrontan es, a no dudarlo, el fracaso escolar. Este trae muy se- rias consecuencias en la vida del estudiante. Si se toma en consideración que una de las aspiraciones de los muchachos es la de sentirse importante y la de lograr prestigio y fama, fácil será comprender el impacto de un fracaso.

Si la educación media tuviera por objeto sólo la instrucción, los fracasos escolares deberían medirse por el número de reprobados. Pero de sobra sabemos que sus objetivos son mucho más amplios que la simple enseñanza y el aprendizaje.

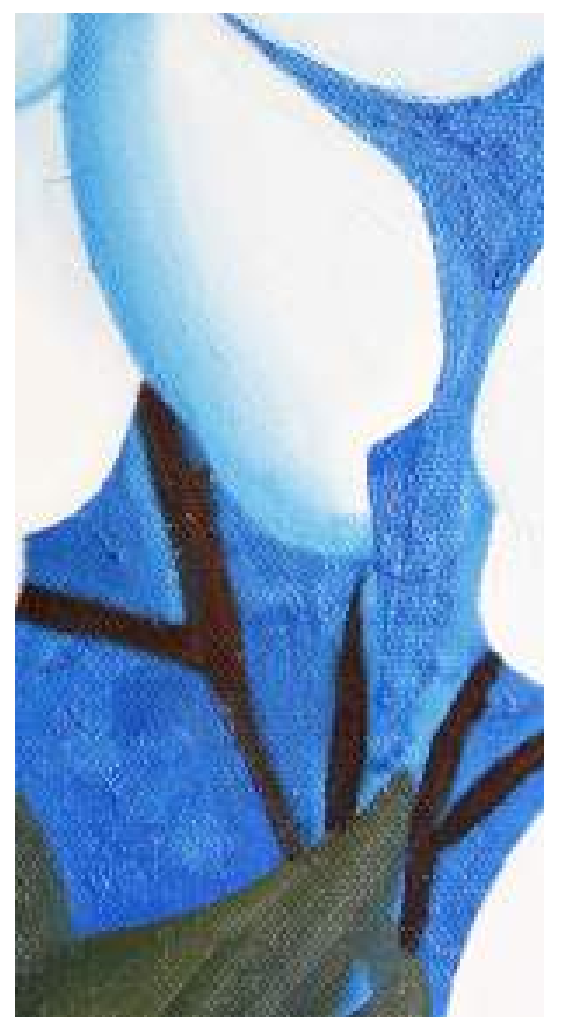

Los fracasos en la educación pueden ser reales 0 aparentes. Importan tanto los relativos al aprendizaje, como los que se refieren a la conducta y a la personalidad. Una situación de fracaso provoca la angustia del escolar. Le preocupa el deterioro que sufre su prestigio frente a sus compañeros, así como la reacción que puedan tener sus padres y familiares.

En un problema de esta naturaleza es necesario que los padres asuman una actitud comprensiva. Si el muchacho sabe que no encuentra en su hogar una disposición de franco entendimiento, su problema adquirirá características de gravedad. Muy frecuentemente, la evasión o fuga del hogar obedece a esta circunstan- 
cia. Si en algún momento necesita el adolescente sentirse amparado por quienes considera personas de mayor experiencia, es cuando sufre un tropiezo o descalabro en sus actividades escolares.

En no pocas ocasiones, más que culpar al muchacho de un tropiezo en sus estudios, debemos responsabilizar al hogar por su falta de atingencia y de ayuda al joven estudiante. Este necesita estímulo, tiempo suficiente, lugar adecuado, tranquilidad hogareña y sobre todo, un ejemplo de responsabilidad de parte de las personas maduras.

\section{C). La Formación del Carácter}

No creo que esté por demás insistir en que la finalidad de la educación media, más que instructiva, es formativa. El ideal de la escuela es ayudar a los muchachos a formar su propia personalidad. El temperamento y el carácter forman parte de ella.

El temperamento es algo natural, nacemos con él o lo desarrollamos luego, afirmándolo 0 atenuándolo. El carácter, al contrario, no es meramente lo que somos, sino lo que queremos ser y más aún lo que debemos ser. El temperamento depende de nuestra herencia biológica y, en cambio, el carácter se mide con un criterio de valores y se realiza por un esfuerzo de la voluntad. El carácter es el coronamiento de la personalidad.

\section{D). Lucha contra el Medio Ambiente}

Nadie ignora la gran influencia que tiene el ambiente físico y social sobre la educación. El mundo actual presenta a la juventud innumerables tentaciones que la seducen y la inclinan por senderos equivocados.
Los múltiples medios de difusión del pensamiento: cine, prensa, radio, televisión, teatro, etc., tan útiles para el fomento de la cultura son, a la vez, peligrosos medios para desviar al adolescente por el mal camino. Respiramos un ambiente malsano de relajación de las buenas costumbres.

En el seno de la familia podemos encontrar el mejor baluarte contra el ambiente malsano. Para ello es preciso que impere en el hogar la armonía, el ejemplo, las buenas costumbres y el sentido de responsabilidad.

Es común que nos sorprendamos de las extravagantes actitudes de muchos jóvenes y adolescentes. En efecto, la música moderna que gusta a la juventud, los cambios que introducen en su forma de vestir, el raro lenguaje que usan y algunas otras manifestaciones de la moderna vida juvenil, deben ser examinadas a la luz de la influencia del medio y como una consecuencia de la crisis de valores del mundo contemporáneo.

No se trata de buscar que los jóvenes de hoy sean idénticos a los de hace cincuenta años. Los tiempos cambian, las modas, los estilos literarios, la música y las formas de divertirse. Se trata de que se hagan imperar, sobre las superficialidades y tendencias equivocadas, los principios de bien, justicia, belleza, bondad y respeto a las formas honestas de vivir.

Al adolescente deben dársele razones para creer que nos respetamos a nosotros mismos y que también lo respetamos a él.

Tiene derecho a esperar de nosotros que tengamos confianza no sólo en nuestras propias actitudes, sino tam- bién en su capacidad de hallar una filosofía válida para sí mismo.

Debe proporcionársele pruebas de que, siempre que sea posible, le daremos nuestra ayuda. Debemos tratar de protegerlo con inteligencia, y de concederle suficiente libertad como para facilitar su maduración. Antes que nada, debemos darle tiempo a que trace los planes de su mundo adulto. Si queremos ayudarlo no podemos tratarlo como un niño, pero tampoco podemos exigirle que sea un adulto.
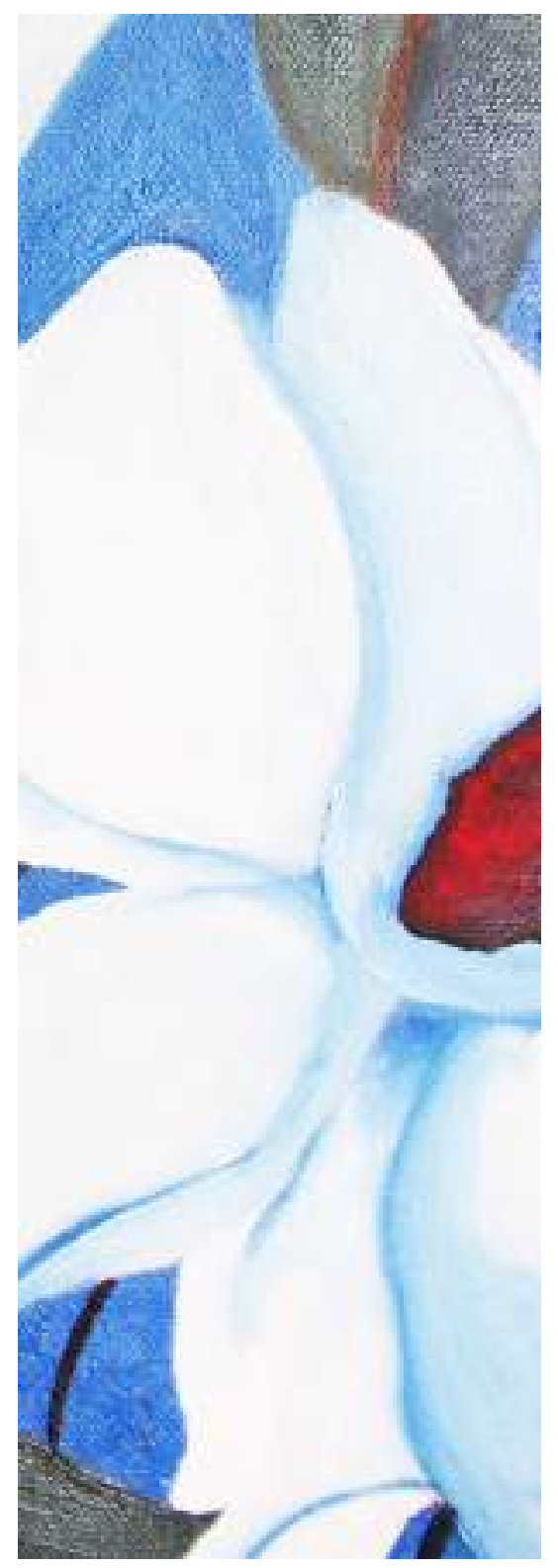